\title{
Association of gastro-oesophageal reflux disease with oesophageal stricture: what can be done to prevent it?
}

\author{
Abdulzahra Hussain ${ }^{1,3}$,Tahir Chohan ${ }^{1}$, Ali Adnan ${ }^{4}$,Shamsi El-Hasani ${ }^{1}$,Maxwell Asante ${ }^{2}$ \\ ${ }^{1}$ Upper GI Unit, General surgery department \\ ${ }^{2}$ Gastroenterology unit, Department of medicine, Princess Royal University Hospital.Orpington, Greater London, BR6 8ND \\ ${ }^{3}$ Senior lecturer,King's College Medical School, London \\ ${ }^{4}$ Otolarngology, Head and neck department.Sahlgrenska university hospitalGröna stråket 9.41345 Gothenburg.Sweden
}

\section{Email address:}

azahrahussain@yahoo.com(A. Hussain)

\section{To cite this article:}

Abdulzahra Hussain,Tahir Chohan, Ali Adnan,Shamsi El-Hasani,Maxwell Asante. Association of Gastro-Oesophageal Reflux Disease with Oesophageal Stricture: What can be Done to Prevent It. Journal of Surgery. Vol. 1, No. 2, 2013, pp. 18-21.

doi: $10.11648 /$ j.js.20130102.13

\begin{abstract}
Objectives: GORD is associated with benign oesophageal stricture. Endoscopic management of which is safe, effective and commonly applied. The aim of this study is to assess the causes of benign oesophageal stricture,the outcome of endoscopic management and to explore the literatures on ways of preventions. Patients and Methods: Data from our endoscopy unit was reviewed using unisoft software. Seventy -one patients who have been diagnosed with oesophageal strictures during March 2006-January 2012,were selected for this study. Twelve oesophageal cancers, 4 patients with achalasia and 6 patients with anastomotic stricture were excluded. The data was collected from case notes of the remaining forty-nine patients. Results: Forty-nine patients were diagnosed with symptomatic benign stricture due to reflux disease and inflammation (47 and 2 patients respectively). The age range was 38-92 (mean 59), 17(34.7\%) women and $32(65.3 \%)$ men were included. $42(85.71 \%)$ patients underwent dilatation, of which $88.7 \%$ had $1-4$ dilatations (mean of 2 dilatations). The remaining 14.28\% (6 patients) had very tight strictures and each had 5-7 dilatations. One (2.04\%) patient had anti-reflux surgery. Six (12.24\%) patients were treated conservatively using proton pump inhibitors and they didn't need dilatation. There were 34 patients developed minor morbidities such as chest pain (11\%); minor bleeding (15) and nausea (3\%),no oesophageal perforation or other major complications were reported. Conclusions: Endoscopic dilatation for benign oesophageal stricture is a safe and an effective procedure. Follow up of younger patients are necessary to achieve satisfactory symptomatic relief and to prevent advanced and severe stricture developing at a later age.
\end{abstract}

Keywords: Oesophageal Stricture, Benign Oesophageal Stricture, Dilatation, Gastro-Oesophageal Reflux Disease

\section{Introduction}

Oesophageal strictures are caused by a variety of pathologies including gastro-oesophageal reflux disease (GORD), inflammation, trauma, neuromuscular and autoimmune disease processes, post oesophageal surgery, cancer, and congenital malformation. Most benign oesophageal strictures (OS) are due to GORD. This affects different age groups but significant numbers of patients are the young population. Current guidelines of British Society of Gastroenterology (BSG) do not support routine endoscopy for GORD patients and Proton Pump Inhibitors (PPIs) are prescribed by general practitioners (GPs) to manage the majority [1]. Thus the full burden of OS (especially the mild one) is expected to be less represented in the current gastroenterology and upper GI surgical practices. [2]

OS can be localised or diffuse. It can be short, simple or complex; more than two centimetres, or tortuous. Tighter strictures of less than 10 millimeters usually do not allow the scope to pass through [3]. Upper gastrointestinal endoscopy, fluoroscopy or upper gastrointestinal series (barium and gastrograffin swallows) are frequently used to define the diagnosis, severity and guide on therapeutic options.

Endoscopic dilatation is the commonest method of management and is regarded as a safe and effective therapeutic procedure even for avery tight stricture [4]. The number of sessions of endoscopic or fluoroscopic dilatation depends on the severity of the OS and symptoms [5]. The incidence of major complications such as oesophageal 
rupture has been reported to be as high as $14.7 \%$ following fluoroscopic dilation (with only a minority needing active management), whilst in endoscopic dilatation the incidence of oesophageal perforation is $0.1-0.4 \%[6,7]$ The aim of this study was to assess the causes of benign oesophageal stricture, its management and how to predict and prevent advanced stricture in young population.

\subsection{Materials and Methods}

The endoscopy data were reviewed using unisoft software during January 2012.Seventy-one patients who have been diagnosed with oesophageal strictures were selected for this study covering March 2006-January 2012.Twelve patients were diagnosed with carcinoma, 4 with achalasia and 6 with OS following upper gastrointestinal surgery were excluded. Data of the remaining Forty-nine English patients were obtained from case records and analysed.

Dilatation technique: Oesophago-gastroduodenoscopy (OGD) was performed to assess the site, length, and severity of the OS. The rule of 3[8] is adopted and increment by $1 \mathrm{~mm}$ in is used in series of three dilatations per session, in all patients. A guide wire was inserted under vision to cross the OS in mild to moderately tight strictures. Fluoroscopy was used to screen the wire across the OS in tight and complex strictures. The balloon was inserted over the guide wire. The optimum position was checked with OGD or radiology. After satisfactory positioning, the balloon was inflated and deflated and the site of the stricture was checked for any possible complications e.g. perforation or bleeding. The scope was then retrieved and the patient was observed for few hours before discharge. Patients with clinical or endoscopic suspicion of major complications were admitted.

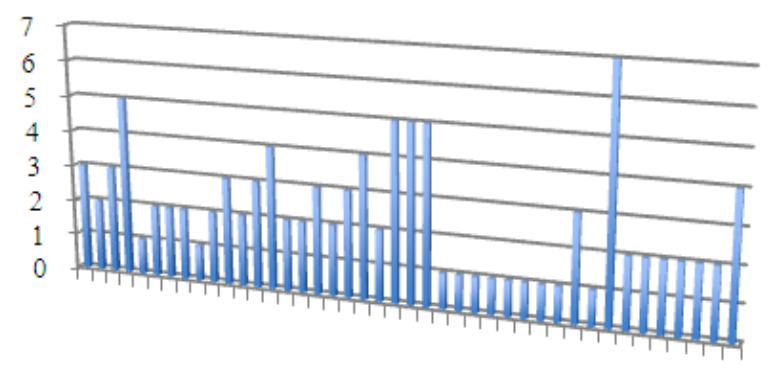

Figure (1)Number of dilatation for each of 42 patients

The patients were seen in the outpatient clinic in 4-6 weeks, 3-6 months and then either discharged or arrangement for long follow up was adopted, if they have a tight and complex stricture. Any patient, who was symptomatic, was offered another OGD +/_ dilatation.

\subsection{Results}

49 patients were diagnosed with symptomatic benign stricture. 47 were due to reflux disease and 2 were due to eosinophilic oesophagitis. The age ranged between 38-92 (mean 59). 17(34.7\%) were women and 32(65.3\%) were men .The stricture site ranged from $20-40 \mathrm{~cm}$ from the incisor teeth and the length of the stricture was $0.5-5 \mathrm{~cm}$ (average $1 \mathrm{~cm}$ ). Other associated features are shown in table (1). The main presentations were dysphagia(54.7\%)and dyspepsia (39.6\%)(table 2).

Table (1)Associated features of the OS. The percentage are taken per episode of the endoscopic findings which indicates two or more diagnosis on the same patient

\begin{tabular}{cc}
\hline Schatzki's ring & $8(16.3 \%)$ \\
Barrett's & $2(4.08 \%)$ \\
Dysplasia & $3(6.12 \%)$ \\
Hiatus hernia & $42(85.71 \%)$ \\
\hline
\end{tabular}

Table (2) Main presentation for every patient

\begin{tabular}{cc}
\hline Presentation & NO/\% \\
\hline Dysphagia & $29(59.18)$ \\
Dyspepsia & $21(42.85)$ \\
Malena & $1(2.04)$ \\
Weight loss & $1(2.04)$ \\
Chest pain & $1(2.04)$ \\
\hline
\end{tabular}

$42(85.7 \%)$ had dilatation (figure $1 \&$ table 3$)$. Of these, six (14.28\%) patients (age range of 83-91 years) had very tight strictures and required 5-7 (average 5 sessions) dilatations. The remaining $36(85.71 \%)$ patients (age range of 38-85, mean of 59 years) had between 1-4 dilatations (average 2 sessions). Their age was ranged between 38 and 85 (average 59 years). One $(2.04 \%)$ patient had anti-reflux surgery (table 3). Six (12.24\%) patients were treated conservatively using PPIsand they didn't need dilatation.

Table (3) interventions and follow up

\begin{tabular}{cc}
\hline Intervention & No of patients $/ \%$ \\
\hline Endoscopic dilatation & $42(85.71)$ \\
Anti-reflux surgery & $1(12.04)$ \\
Discharged & $15(30.61)$ \\
Lost to follow up & $8(16.32)$ \\
Continuous follow up & $30(61.22)$ \\
\hline
\end{tabular}

Morbidity included lower chest pain, nausea "minor bleeding at the stricture site and hypotension". No esophageal perforation or other major complications were reported . The follow up plan is shown in table 3.Five $(10.20 \%)$ patients died during the follow up period for other reasons including cardiac events and strokes (table 4).

\section{Discussion}

In Europe and North America, benign OS is commonly caused by recurrent peptic and to a lesser degree by non-peptic pathology such as corrosive injury, eosinophilicoesophagitis, post-surgery, and trauma $[9,10]$. In this cohort of patients, GORD was the main associated risk factor for benign OS. In other parts of the world such as Asia, erosive oesophagitis, and its aftermath OS is much less compared to Western patients [11]. The diagnosis of OS is relatively easy but the main issue is to exclude a 
malignant process, thus biopsy of the stricture is recommended [12]. Endoscopic dilatation is the cornerstone of management of benign OS [13, 14]. Fluoroscopic or radiological guided dilatation is also effective with comparable results to endoscopic dilatation although conflicting evidence of complication, have been reported [5]. Additionally, endoscopic plasma lasers application, electro-coagulation, stenting and steroid injection are also reported. Surgery has been suggested for severe and very tight benignOS[15, 16].

Recently in an interesting study of more than 150,000 oesophagogastroduodenoscopy (OGD) from Sandwell, UK the authors found that reflux oesophagitis, Barrett's oesophagus (BO) and stricture were more common in absolute and relative terms amongst younger men than younger women [17]. Although age was an independent factor, it has been implicated as a risk factor for oesophageal erosive changesbecause of alcohol consumption and smoking [18]. Asymptomatic erosive oesophagitis (which is the pre-stage of benign OS) was strongly associated with an age greater than 60 years in an Asian population [19].

Table (4) morbidity and mortality

\begin{tabular}{lc}
\hline Complication & Number (\%) \\
\hline Chest pain & $11(26)$ \\
Nausea & $05(11.3)$ \\
Minor bleeding & $15(35.7)$ \\
Hypotension & $03(07.1)$ \\
Oesophageal rupture & $\mathrm{Nil}$ \\
Major bleeding & $\mathrm{Nil}$ \\
Stroke & $2(4.08)$ deaths \\
Colonic cancer & $1(2.04)$ death \\
Myocardial infarction & $2(4.08)$ deaths \\
\hline
\end{tabular}

An American study of 7287 patients with OS who underwent dilatation showed a male predominance [20]. The same trend is also noticed in our patients with a mean age of 59 years. Others have shown this as well [21].

One may suggest that increasing awareness amongst General Practitioners (GPs) or early referral of young patients with dyspepsia may increase the detection of complicated GORD such as OS. Interestingly, however, a study from Finland suggested that increasing GP referral for endoscopy did not increased the detection of peptic oesophagealstricture [22]. Our study raises the question of how to manage young patients who have long-standing reflux disease in order to prevent $\mathrm{OS}$ at a later age. We think that OS secondary to peptic pathology or GORD is a preventable disease when the diagnosis is made at an early age and a strict follow up is applied. In the literature there appears to be no study that addresses the relationship between the age, gender and complicated GORD or peptic stricture and how to prevent it.

Eosinophilicoesophagitis was diagnosed as a cause of OS in two of our patients. This association was reported in the literature and was identified as a risk of oesophageal perforation during dilatation, although others have reported no major complications in a large number of patients who underwent endoscopic dilatation [23-25].

\subsection{Limitations of the Study}

1.Power of the study: Although this is a relatively small study represented consequent series of patients over 6 years, nevertheless it showed safety and efficacy of the used dilatation techniques.

2.Bias: The study included consequent series of patients and therefore there was no selection bias. Senior clinicians at consultant and senior registrar level undertook clinical assessment of the patients. The indication of dilatation was dysphagia in all cases. Decision to dilate or not was mainly clinical one but radiology and endoscopy were helpful for full assessment.

Bias in reporting complications was eliminated to a large extent. There were no major complications and death due to dilatations technique. Minor complications were reported as in the case note of every patient. It may be possible that some minor complications that happened during the procedure were not reported and this may indicate a limited degree of bias.

3.Assessment of the outcomes: This was performed by authors and not by independent, blinded investigator. This perhaps one of the weak points in the retrospective studies and not specific for ours.

4.Follow up and mortality: The follow up of patients was arranged based on the severity of the strictures. Patients who were asymptomatic after dilatation for three visits of 6 months apart were discharged. An arrangement of long follow up was undertaken for any patient who was diagnosed with tight or complex stricture.

Mortality of 5 patients during the period of the study and after 30 days of last dilatation was reported. The mortality was not related to the procedure and all deaths reported for cerebrovascular accidents and ischemic heart disease.

\section{Conclusions}

This study confirmed that male predominance; a relatively young age and reflux or peptic injury are the common risk factors for the development of benign esophageal stricture. Endoscopic oesophageal dilatation is a safe and effective technique for management of these patients, even for complex strictures. Strict follow up for early detection of benign oesophageal stricture in the young population is suggested to prevent progression to complex stricturing.

\section{Acknowledgements}

Te authors appreciate the efforts of Miss Katy Baple for checking the language of the paper.

\section{Disclosure}


All authors confirmed no conflict of interest of any kind and no financial links with any organization.

\section{References}

[1] S A Riley, S E A Attwood Guidelines on the use of esophageal dilatation in clinical practice. Gut 2004; 53(Suppl I): $\mathrm{i} 1-\mathrm{i} 6$

[2] H. B. El-Serag, M. Lau. Temporal Trends in New and Recurrent Oesophageal Strictures in a Medicare Population Aliment PharmacolTher. 2007;25:1223-1229.

[3] Chiu YC, Hsu CC, Chiu KW,Chuah SK, Changchien CS, Wu $\mathrm{KL}$,et al. Factors influencing clinical applications of endoscopic balloon dilation for benign esophageal strictures. Endoscopy. 2004; 36:595-600.

[4] Kabbaj N, Salihoun M, Chaoui Z, Acharki M, Amrani N. Safety and outcome using endoscopic dilatation for benign esophageal stricture without fluoroscopy.World J GastrointestPharmacolTher.2011; 2: 46-9.

[5] Lew RJ, Kochman ML.A review of endoscopic methods of esophageal dilation. J ClinGastroenterol. 2002; 35:117-126.

[6] Fan Y, Song HY, Kim JH, Park JH, Ponnuswamy I, Jung HY,et al. Fluoroscopically guided balloon dilation of benign esophageal strictures: incidence of esophageal rupture and its management in 589 patients.AJR Am J Roentgenol.2011; 197: 1481-6.

[7] Hernandez LV, Jacobson JW, Harris MS. Comparison among the perfo- ration rates of Maloney, balloon, and savary dilation of esophageal strictures. GastrointestEndosc 2000;51:460-2

[8] Guidelines on the use of oesophageal dilatation in clinical practice.S A Riley, S E A Attwood.Gut 2004;53(Suppl I):i1-i6

[9] Pregun I, Hritz I, Tulassay Z, Herszényi L. Peptic esophageal stricture: medical treatment.Dig Dis.2009; 27: 31-7.

[10] Vetter S, Jakobs R, Weickert U. [Benign non-peptic esophageal stenosis: causes, treatment and outcome in routine clinical practice].Dtsch Med Wochenschr. 2010;135:1061-6.

[11] Cheung TK, Wong BC, Lam SK. Gastro-oesophageal reflux disease in Asia : birth of a 'new' disease.Drugs. 2008;68:399-406.

[12] NawalKabbaj, MounaSalihoun, ZakiaChaoui, Mohamed Acharki, and NaïmaAmrani .Safety and outcome using endoscopic dilatation for benign esophageal stricture without fluoroscopy.World J GastrointestPharmacolTher. 2011 ; 2: 46-49

[13] De la Garza González SJ, García RG. [Update in the endoscopic management of benign esophageal stenoses]. Rev
Gastroenterol Mex. 2005; 70: 20-4.

[14] deWijkerslooth LR, Vleggaar FP, Siersema PD. Endoscopic management of difficult or recurrent esophageal strictures. Am J Gastroenterol. 2011;106:2080-91.

[15] Kim JH, Shin JH, Song HY. Benign strictures of the esophagus and gastric outlet: interventional management.Korean J Radiol.2010 ;11:497-506.

[16] Shen KR, Harrison-Phipps KM, Cassivi SD, Wigle D, Nichols FC 3rd, Allen MS,et al. Esophagectomy after anti-reflux Surg. $2010 ; 139: 969-75$.

[17] Menon S, Jayasena H, Nightingale P, Trudgill NJ. Influence of age and sex on endoscopic findings of gastrooesophageal reflux disease: an endoscopy database study.Eur J GastroenterolHepatol. 2011;23:389-95.

[18] Lee SJ, Jung MK, Kim SK, Jang BI, Lee SH, Kim KO,et al. [Clinical characteristics of gastroesophageal reflux disease with esophageal injury in korean: focusing on risk factors].Korean J Gastroenterol. 2011;57:281-7.

[19] Cho JH, Kim HM, Ko GJ, Woo ML, Moon CM, Kim YJ, et al.Old age and male sex are associated with increased risk of asymptomatic erosive esophagitis: analysis of data from local health examinations by the Korean National Health Insurance Corporation.JGastroenterolHepatol. 2011;26:1034-8

[20] Olson JS, Lieberman DA, Sonnenberg A. Practice patterns in the management of patients with esophageal strictures and rings.GastrointestEndosc. $2007 ; 66: 670-5$

[21] Pereira-Lima JC, Ramires RP, Zamin I Jr, Cassal AP, Marroni CA, Mattos AA.Endoscopic dilation of benign esophageal strictures: report on 1043 procedures.Am J Gastroenterol.1999;94:1497-501.

[22] Mäntynen T, Färkkilä M, Kunnamo I, Mecklin JP, Juhola M, Voutilainen M.The impact of upper GI endoscopy referral volume on the diagnosis of gastroesophageal reflux disease and its complications: a 1-year cross-sectional study in a referral area with 260,000 inhabitants.Am J Gastroenterol.2002; 97:2524-9.

[23] Kaplan M, Mutlu EA, Jakate S, Bruninga K, Losurdo J, LosurdoJ,et al. Endoscopy in eosinophilicesoph-agitis: "feline" esophagus and perforation risk. ClinGastroenterolHepatol 2003;1:433-7.

[24] Francis D, Schreiber J, Dierkhising RA, Talley NJ, Smyrk TC, Alexander JA.Occurrence of and risk factors for complications after endoscopic dilation in eosinophilicesophagitis.Jung KW, Gundersen N, Kopacova J, Arora AS, Romero Y, KatzkaGastrointestEndosc. 2011;73:15-21

[25] Ally MR, Dias J, Veerappan GR, Maydonovitch CL, Wong RK, MoawadFJ.Safety of dilation in adults with eosinophilicesophagitis.Dis Esophagus. 2012 ;7. doi: 10.1111/j.1442-2050.2012.01363. 